University of Nebraska - Lincoln

DigitalCommons@University of Nebraska - Lincoln

Educational Psychology Papers and

Publications

Educational Psychology, Department of

2012

\title{
A longitudinal study of school connectedness and academic outcomes across sixth grade
}

\author{
Kate Niehaus \\ University of Louisville, kate.niehaus@sc.edu \\ Kathleen Moritz Rudasill \\ University of Nebraska-Lincoln, kmrudasill@vcu.edu \\ Christopher R. Rakes \\ Institute of Education Sciences, US Dept. of Education
}

Follow this and additional works at: https://digitalcommons.unl.edu/edpsychpapers

Part of the Child Psychology Commons, Cognitive Psychology Commons, Developmental Psychology Commons, and the School Psychology Commons

Niehaus, Kate; Rudasill, Kathleen Moritz; and Rakes, Christopher R., "A longitudinal study of school connectedness and academic outcomes across sixth grade" (2012). Educational Psychology Papers and Publications. 158.

https://digitalcommons.unl.edu/edpsychpapers/158

This Article is brought to you for free and open access by the Educational Psychology, Department of at DigitalCommons@University of Nebraska - Lincoln. It has been accepted for inclusion in Educational Psychology Papers and Publications by an authorized administrator of DigitalCommons@University of Nebraska - Lincoln. 


\title{
A longitudinal study of school connectedness and academic outcomes across sixth grade
}

\author{
Kate Niehaus $^{\mathrm{a}, *}$, Kathleen Moritz Rudasill ${ }^{\mathrm{b}}$, Christopher R. Rakes ${ }^{\mathrm{c}}$ \\ a Department of Educational and Counseling Psychology, University of Louisville, USA \\ b Department of Educational Psychology, University of Nebraska-Lincoln, USA \\ ${ }^{\mathrm{c}}$ Institute of Education Sciences, USA
}

\section{A R T I C L E I N F O}

\section{Article history:}

Received 28 March 2011

Received in revised form 10 March 2012

Accepted 16 March 2012

\section{Keywords:}

School connectedness

Academic outcomes

Middle school

High poverty students

Latent growth curve modeling

\begin{abstract}
A B S T R A C T
The current longitudinal study examines the extent to which school connectedness (i.e., students' perceptions of school support and the number of adults with whom they have a positive relationship) is associated with academic outcomes across sixth grade for students from high poverty neighborhoods. Data were collected from 330 sixth-grade students attending two middle schools in a large public school district. Specifically, students completed a survey to assess their perceived connection to the school environment, and academic information regarding students' grades, attendance, and discipline referrals was obtained from school records. Results from latent growth curve modeling showed that, on average, students' perceptions of school support declined significantly across the sixth-grade year. However, students who reported less decline, or growth, in school support across sixth grade had higher academic achievement at the end of the year than students who reported more decline in school support. Sixth-grade boys were at a greater risk for negative outcomes (i.e., lower school support, lower GPAs, and more discipline referrals) across the school year than girls. Results point to the importance of perceived connectedness to school in helping economically disadvantaged students experience a safe and successful transition to middle school.

(C) 2012 Society for the Study of School Psychology. Published by Elsevier Ltd. All rights reserved.
\end{abstract}

\footnotetext{
is This research was funded by a university-sponsored research incentive grant. The authors would like to thank the middle school students, teachers, and administrators who were involved in data collection and those individuals in the school system's research and planning office who helped gather archival data from student records.

* Corresponding author at: Department of Educational and Counseling Psychology, College of Education and Human Development, University of Louisville, Louisville, KY, 40292, USA.

E-mail address: kate.niehaus@louisville.edu (K. Niehaus)

Action Editor: Craig Albers
}

0022-4405/\$ - see front matter (C) 2012 Society for the Study of School Psychology. Published by Elsevier Ltd. All rights reserved. doi:10.1016/j.jsp.2012.03.002 


\section{Introduction}

The transition from elementary to middle school can be difficult for youth as they face not only a change in their school and social environments but also a multitude of physical and emotional changes commensurate with the onset of puberty (Eccles, Lord, Roeser \& Barber, 1997). This transitional period is often marked by a variety of negative outcomes for young adolescents, including lower self-esteem and self-concept (Wigfield, Eccles, Mac Iver, Reuman \& Midgley, 1991), lower achievement motivation (Anderman, Maehr \& Midgley, 1999), and declining school performance (Alspaugh, 1998). Students living in poverty are at an even greater risk for academic failure and school-related problems as adolescents (Pagani, Boulerice, Vitaro \& Tremblay, 1999). Particularly for youth who grow up in impoverished inner city neighborhoods, increased exposure to dangerous activities (e.g., drug trafficking and violence), higher stress levels, and greater feelings of hopelessness about the future are some of the environmental factors that place students at risk for negative academic and behavioral outcomes (Bolland et al., 2007). Thus, there is often an emphasis on survival, rather than academic success, in high poverty urban environments (Bolland et al., 2007) that may position schools as unpleasant or unimportant environments for students (Battistich, Solomon, Kim \& Watson, 1995). Taken together, evidence shows that the transition to middle school has important implications for students' academic, social, and psychological wellbeing (Wigfield, Lutz \& Wagner, 2005); thus, this period is a critical area of study, particularly for students who are at risk for academic problems due to poverty.

Existing research with early middle school students (defined in this study as students who begin middle school in sixth grade) indicates that students' perceptions of school connectedness (e.g., perceptions of teacher and peer support) are related to emotional, behavioral, and academic outcomes. For example, decrements in students' perceptions of teacher and peer support predicted more depressive symptoms and behavior problems in a study examining these constructs longitudinally from sixth to eighth grade (Way, Reddy \& Rhodes, 2007). Likewise, Jia et al. (2009) found that student perceptions of teacher and peer support were positively related to academic achievement in a cross-sectional study of middle school children from the United States and China. There is also a substantial body of literature supporting the idea that students' relationships with teachers are important for positive student outcomes in middle school (Davis, 2003, 2006; Furrer \& Skinner, 2003; Rudasill, Reio, Stipanovic \& Taylor, 2010; Ryan, Stiller \& Lynch, 1994). However, few of these studies have focused on the experiences of students from lower socioeconomic backgrounds, leaving a gap in the literature regarding the relationship between school connectedness and academic outcomes for underprivileged students. The purpose of the present study, then, is to examine students' perceptions of school connectedness across sixth grade as they relate to academic outcomes and behavior at the end of the year for students living in high poverty neighborhoods.

\subsection{Theoretical foundations}

The powerful role of students' perceptions of connection to school is further supported by established theories of social connectedness. In their extensive literature review, Baumeister and Leary (1995) asserted that feelings of belonging are a fundamental human need and that all individuals are inherently motivated to connect with others and form social bonds. They emphasized that many negative outcomes (e.g., psychological distress, increased health problems, and lower ability to manage stress) result when individuals are not socially connected, providing support for the argument that feelings of belonging are not only desired but needed. Baumeister and Leary concluded that "the desire for interpersonal attachment may well be one of the most far-reaching and integrative constructs currently available to understand human nature" (p. 522).

Another contemporary theory of human motivation, self-determination theory (Deci \& Ryan, 2000), also supports the importance of students' feelings of connectedness to school. Using a tripartite model to explain individual behavior, Deci and Ryan (2000) proposed that human behavior is motivated by three essential needs: competency, autonomy, and relatedness. Although these are psychological rather than physiological needs, Deci and Ryan (2000) argued that they are critical for intrinsic motivation, positive affective experiences, and overall mental wellbeing. The need for relatedness (i.e., the innate human desire to form secure and supportive relational networks in various environmental contexts) is especially pertinent to the present examination of school connectedness, which recognizes that school is a primary environmental context for children. 


\subsection{Importance of school connectedness}

As would be expected from theories of social connectedness (Baumeister \& Leary, 1995; Deci \& Ryan, 2000), students' perceptions of connection to school have significant implications for their behaviors inside and outside the classroom. With regard to academic performance, previous research shows that adolescents who perceive a positive school environment and share positive relationships with their teachers tend to have higher grades (Crosnoe, Johnson \& Elder, 2004; Davis, 2006; Roeser, Midgley \& Urdan, 1996), higher classroom motivation (Davis, 2006; Patrick, Ryan \& Kaplan, 2007; Ryan et al., 1994), higher academic self-efficacy (Roeser et al., 1996), and more cognitive, emotional, and behavioral engagement at school (Furrer \& Skinner, 2003; Patrick et al., 2007; Ryan et al., 1994). In their longitudinal study of elementary, middle, and high school students, Catalano, Haggerty, Oesterle, Fleming and Hawkins (2004) found that students who report higher levels of bonding to school (i.e., attachment to school and commitment to school tasks) not only have better grades and achievement test scores but are also less likely to repeat a grade or dropout of high school. Similarly, students who perceive supportive teacher relationships tend to have fewer behavioral problems that interrupt academic work at school (e.g., school absenteeism, suspension, or expulsion; Crosnoe et al., 2004; Sanders \& Jordan, 2000; Way et al., 2007). Research focusing specifically on sixth-grade students has shown that positive student-teacher relationships are related to more responsible classroom behavior (Wentzel, 2002), while student-teacher conflict is correlated with higher rates of misbehavior and disrespectful acts in the classroom (Davis, 2006).

Other research has shown that early adolescents who feel appreciated by their teachers tend to be more interested in classroom activities, while also feeling more comfortable and happy in class than students who believe they are unimportant to their teachers (Furrer \& Skinner, 2003). Additionally, middle school students tend to maintain higher academic motivation and interest when they perceive their teachers as helpful and emotionally supportive, and as providing a safe classroom environment and clear expectations for student behavior (Wentzel, Battle, Russell \& Looney, 2010). In general, students who feel connected to their school environments not only have more positive academic outcomes, but are also less likely to engage in risky behaviors (Catalano et al., 2004; Diaz, 2005; Resnick et al., 1997; Rudasill et al., 2010; Voisin et al., 2005) and have better social-emotional outcomes and psychological health (Demaray, Malecki, Rueger, Brown \& Summers, 2009; Reddy, Rhodes \& Mulhall, 2003; Rueger, Malecki \& Demaray, 2010; Suldo et al., 2009; Van Ryzin, Gravely \& Roseth, 2009; Way et al., 2007). As is evidenced by these research findings, school connectedness is an important construct to consider when examining a variety of student outcomes, particularly those related to academic and school success. However, it is also important to note that the associations between school connectedness and student outcomes are not causal, and therefore, we cannot be certain about the directionality of these results. For example, it could be that higher achieving students are able to build stronger relationships with teachers, that stronger student-teacher relationships enhance student achievement, or that there is a reciprocal, mutually reinforcing relationship between school connectedness and achievement.

\subsection{Student characteristics and perceptions of school connectedness}

Evidence has also suggested that individual characteristics are related to students' perceptions of school connectedness. For example, Davis (2006) found that students with higher academic motivation, self-regulation, social competence, and understanding of their identity as a student tend to have closer relationships with their teachers. Past research has also shown that gender is a consistent predictor of perceptions of school connectedness in that girls have a higher sense of relatedness with their teachers (Furrer \& Skinner, 2003), stronger feelings of school belonging (Diaz, 2005), and more positive perceptions of teacher support (Rueger et al., 2010; Wentzel et al., 2010) than do boys. In addition, teachers tend to rate their relationships with girls more positively than with boys (Ewing \& Taylor, 2009). Boys, on the other hand, are more likely to report that they have no one at school with whom they can discuss emotional concerns, leaving them at a greater risk for poor school adjustment (Ryan et al., 1994). Interestingly, Furrer and Skinner (2003) found that while boys tend to have more distanced relationships with teachers, the student-teacher relationship may be even more critical for boys in predicting certain outcomes such as school engagement. Similarly, research shows that although sixth-grade students feel 
less connected to their teachers than fifth-grade students, the student-teacher relationship is a better predictor of school engagement for sixth-graders than it is for fifth-graders (Furrer \& Skinner, 2003). Thus, student characteristics, such as gender and age, seem to contribute to both the quality and importance of the student-teacher relationship, with boys and sixth-grade students being particularly at risk for negative outcomes when teacher relatedness is low.

Students' socioeconomic status is another individual variable related to perceptions of school connectedness (Crosnoe et al., 2004). Middle and high school students who have more highly educated parents tend to experience more positive student-teacher relationships. Interestingly, while disadvantaged students may have lower-quality relationships with teachers, the student-teacher relationship is more strongly related to their psychological health and school outcomes than it is for students from higher-income families (Olsson, 2009). Other research has shown that students from high poverty schools tend to feel less connected to school in general; however, students in high poverty schools may benefit more from a strong school community than students in low poverty schools (Battistich et al., 1995). Thus, school communities that emphasize social connectedness and caring relationships may be even more important for positive outcomes among low-income student populations.

\subsection{Rationale and purpose of current study}

This exploratory study addresses several gaps in the existing literature on school connectedness. First, the present study is focused specifically on students who are at risk for negative academic and behavioral outcomes due to poverty. A large number of previous studies in this field have been based on samples of students from middle-class socioeconomic backgrounds (e.g., Patrick et al., 2007; Roeser et al., 1996) or from a diverse range of socioeconomic backgrounds (e.g., Catalano et al., 2004; Jia et al., 2009; McNeely \& Falci, 2004; Rueger et al., 2010; Way et al., 2007). A more in-depth examination of school connectedness among students from high poverty neighborhoods is needed. Second, as many previous investigations of school connectedness have been cross-sectional (e.g., Jia et al., 2009; Resnick et al., 1997; Ryan et al., 1994; Wentzel et al., 2010), the longitudinal perspective taken in the present study is a significant strength, providing a better understanding of growth in connection to school across an important transitional period.

Lastly, the definition and measurement of school connectedness are particular strong points of the current study. Currently, there is no clearly established definition of school connectedness, as this term is often grouped and used interchangeably with similar terms such as school climate, school attachment, school bonding, and school engagement (Libbey, 2004). Recent work examining school engagement (Appleton, Christenson \& Furlong, 2008) has noted that students' engagement at school includes cognitive, behavioral, and emotional connections to the school environment. In the current study, we maintain a clear focus on students' emotional connections at school (i.e., feeling supported and connected in their relationships) as we investigate the specific construct of school connectedness.

In recent years, other researchers assessing school connectedness (e.g., Loukas, Roalson \& Herrera, 2010; McNeely \& Falci, 2004; Resnick et al., 1997) have used items from the National Longitudinal Study of Adolescent Health (Add Health) student survey, which defines two primary components of school connectedness: teacher support and social belonging (McNeely \& Falci, 2004). Although teacher support is an important component of school connectedness in the present study as well, the measure of school connectedness in this study also probes students' perceived connections with all adults at school (e.g., principal, librarian, school psychologist). That is, several survey items were worded in such a way that students were able to identify how many adults to whom they felt connected, allowing for a more inclusive perspective of student-adult relationships at school.

Given that sixth-grade students (particularly those at risk for school failure due to poverty; Gutman \& Midgley, 2000) face a variety of difficulties during the transition to middle school and that school connectedness can help buffer against some of these transitional challenges (Davis, 2006; Furrer \& Skinner, 2003; Roeser et al., 1996), the present study sought to examine the role of school connectedness in promoting academic outcomes (i.e., end-of-year grade point average [GPA]) and behaviors (i.e., total absences and discipline referrals during the academic year) among a sample of students from high poverty areas. Additionally, because students' gender, academic achievement, and school connectedness are interrelated (e.g., Catalano et al., 2004; Furrer \& Skinner, 2003; Rueger et al., 2010), student self-reported gender was 
included as a predictor of both school connectedness and academic outcomes. To that end, we addressed the following research questions:

1. Do students' perceptions of school connectedness change across sixth grade and, if so, to what extent does gender (controlling for the school that students attend) explain these changes?

2. Do students' gender (controlling for the school that they attend), initial perceptions of school connectedness (at the beginning of sixth grade), and changes in school connectedness across the year predict academic outcomes (i.e., GPA, number of absences, and number of discipline referrals) at the end of sixth grade?

\section{Method}

\subsection{Participants}

\subsubsection{Student information}

All sixth-grade students from two middle schools in a large, urban public school district were recruited for participation in this study. The school district is located in the Midwestern United States and serves approximately 100,000 students. School district personnel identified these schools for participation in the study because they were similar in that they both served students living in high poverty neighborhoods in the urban area of the district, and administrators in these schools agreed to distribute surveys for the study. School A had a total enrollment of 496 students in sixth through eighth grades. Data from 178 sixthgraders from School A were included in this study, and 98\% of these students were eligible for free or reduced lunch. School B had a total enrollment of 1069 students in sixth through eighth grades. School B offered a competitive magnet program that served approximately one half of the students. Only nonmagnet, sixth-grade students in School B $(n=152)$ were included in this study, $92 \%$ of whom were eligible for free or reduced lunch.

All sixth-grade students at school on the data collection days received surveys to complete. Due to students choosing not to participate, absences on data collection days, and movement to and from schools throughout the year, different numbers of students completed the surveys at each time point. Administrators reported that students in these schools from high poverty neighborhoods were more likely to be transient than students in the district at large. A total of 292 students participated in the fall data collection, 277 students participated in the winter, and 250 students participated in the spring (for a total of 330 students who participated in at least one data collection). In terms of racial/ethnic composition, $35 \%$ of students in the present study were White, $58 \%$ were Black or African American, and $7 \%$ were Hispanic, Asian, or other races or ethnicities.

Patterns of missing data at all three data collection points were analyzed by student gender and school. Independent samples $t$-tests indicated no statistically significant gender differences in missing data at any of the collection points $(p>.05)$. However, students in School A were significantly more likely to have missing data than students in School B for all measures at all three data collection points $(p<.05)$.

\subsubsection{School information}

School-level attendance and suspension information was available for one or two years prior to the school year during which data were collected for this study. For all students at Schools A and B, average daily attendance rates were $92 \%$ and $95 \%$, respectively; the average daily attendance rate for all students in middle schools across the district was $94 \%$. During the previous school year, $7 \%$ of middle school students in the district missed 25 or more days of school. At School A, this percentage was 14\%, and at School B, this percentage was $5 \%$. Suspensions were administered at a rate of 0.24 per student across the district. This rate was lower than the rate at School A ( 0.47 suspensions per student) and higher than the rate at School B ( 0.14 suspensions per student).

Regarding No Child Left Behind state accountability testing, 21\% and 30\% of sixth-grade students at School A displayed proficiency or higher in reading and mathematics, respectively. In School B, 26\% and $23 \%$ of non-magnet sixth-grade students displayed proficiency or higher in reading and mathematics, respectively. These scores are much lower than those found across sixth-graders in the district and the state; $58 \%$ of all sixth-graders in the district achieved at least proficiency level in reading, and $54 \%$ achieved 
at least proficiency level in mathematics. In the state, $68 \%$ of all sixth-graders achieved at least proficiency level in reading, and 65\% achieved at least proficiency level in mathematics.

\subsection{Sources of data}

\subsubsection{Review of records}

Students' GPA, number of discipline referrals, and number of absences, as well as gender, were obtained through school records at the end of the sixth-grade year. Discipline referrals were recorded by district personnel, and this variable reflects the total number of discipline referrals for each student during the sixth-grade school year. Number of absences refers to the number of days each student was absent from school during the sixth-grade year.

\subsubsection{Measures of school connectedness}

School connectedness was measured with an instrument adapted from three sources: the National Educational Longitudinal Study (NELS 88; tapping students' feelings about teacher-student and studentstudent interactions and caring), the Need Satisfaction Scale (LaGuardia, Ryan, Couchman \& Deci, 2000; examining students' feelings of connection and closeness in school), and the Scale of Caring Adult Relationships in School (Jennings, 2003; assessing the number of adults whom students feel connected to in school). Items from the NELS 88 study and the Need Satisfaction Scale ranged from $0=$ definitely not true to $3=$ very true. Items adapted from the Scale of Caring Adult Relationships in School ranged from $0=$ no adults to $4=$ more than 3 adults.

Given that items from three different instruments were combined to form our measure of school connectedness, there was no established or expected factor structure for these items. Thus, we used exploratory factor analysis (EFA) to examine this instrument's factor structure. Principle axis factoring with Promax rotation was first conducted using scores from the imputed data from the spring administration of the instrument. Factor analyses were also conducted with imputed data from the fall and winter administrations of the instrument and similar factor structures emerged. Therefore, only results from analyses with the spring data are reported here. Ordinal responses $(0=$ not true to $3=$ very true) were treated as continuous data because of the assumption that the underlying latent variables had a multivariate normal distribution (Bentler \& Wu, 1995). The initial solution based on the Kaiser criterion had four factors and accounted for 55\% of the variance. We examined the scree plot and conducted a parallel analysis with 1000 sets of random data to determine the number of factors to retain. Parallel analysis identifies the number of factors that would emerge with random data, rendering a more restrictive method of identifying the number of factors emerging from the EFA (O' Connor, 2000).

The scree plot leveled off after two factors, and a parallel analysis suggested no more than three factors. Thus, two more EFAs were conducted: one with three factors forced, and one with two factors forced. Factor solutions from both the two-factor and the three-factor analyses were examined and items that double-loaded (factor loadings on the structure matrix .4 or higher on two or more factors; Stevens, 2002) and items that failed to load on any factor (factor loadings on the structure matrix lower than .4; Stevens, 2002) were eliminated. This elimination process resulted in the loss of one item from the three-factor structure and the loss of two items from the two-factor structure. After re-running the two- and threefactor structures, the two-factor solution, which explained $41 \%$ of the variance, was deemed conceptually and structurally more tenable. Specifically, the third factor in the three-factor solution contained only three items and comprised all items that had been reverse-scored prior to analysis that otherwise fit with the items in the second factor in terms of their content. Thus, the two-factor solution was chosen as the best model. The two factors were positively correlated $(r=.44, p<.001)$. Pattern and structure coefficients for the two-factor structure are shown in Table 1.

The first factor represented student perceptions of relationship strength with all school adults (e.g., teachers, principals, and administrative assistants). This factor included items 1-7 on the survey. A sample item is, "How many adults in this school do you feel really know you as a person?" Internal consistency values at the fall, winter, and spring administrations were $.78, .79$, and .83 , respectively. The second factor represented student perceptions of the degree to which teachers in the school care about students (e.g., "Teachers are interested in students at my school") and students' sense of support in school (e.g., "When I am at my school, I feel free to be who I am"). This factor comprised items 8-11 and items 14-18. Items 12 
Table 1

Pattern and structure matrix factor loadings for two-factor solution using principal axis factoring with Promax rotation.

\begin{tabular}{|c|c|c|c|c|c|}
\hline \multirow[t]{2}{*}{ Item } & & \multicolumn{2}{|l|}{ Factor 1} & \multicolumn{2}{|l|}{ Factor 2} \\
\hline & & Pattern & Structure & Pattern & Structure \\
\hline \multicolumn{6}{|c|}{ How many adults in this school do you: } \\
\hline 1 & Feel really know you as a person? & .64 & .66 & .05 & .33 \\
\hline 2 & Feel support and care about you? & .58 & .69 & .26 & .51 \\
\hline 3 & $\begin{array}{l}\text { Feel comfortable talking to about problems having to do with } \\
\text { your school work? }\end{array}$ & .63 & .64 & .02 & .30 \\
\hline 4 & $\begin{array}{l}\text { Feel comfortable talking to about problems having to do with } \\
\text { other kids at school? }\end{array}$ & .79 & .73 & -.14 & .21 \\
\hline 5 & Feel comfortable talking to about things that happen outside of school? & .78 & .74 & -.09 & .26 \\
\hline 6 & Want to tell when something good happens in your life? & .62 & .68 & .13 & .40 \\
\hline 7 & Want to tell when something bad happens in your life? & .77 & .70 & -.16 & .18 \\
\hline \multicolumn{6}{|c|}{ When I am at my school: } \\
\hline 8 & I feel free to be who I am. & -.02 & .28 & .68 & .67 \\
\hline 9 & I feel like a capable person. & -.14 & .17 & .70 & .64 \\
\hline 10 & I feel cared about. & .25 & .52 & .62 & .73 \\
\hline 11 & I have a say in what happens and can voice my opinion. & -.14 & .17 & .71 & .65 \\
\hline 12 & $\begin{array}{l}\text { I often feel unconnected to other people like teachers and other } \\
\text { students. (reverse scored) }\end{array}$ & .06 & .14 & .19 & .22 \\
\hline 13 & I feel close to people like teachers and other students. & .17 & .32 & .33 & .41 \\
\hline 14 & Teachers are interested in students at my school. & .15 & .38 & .52 & .52 \\
\hline 15 & Students get along well with teachers at my school. & -.02 & .26 & .64 & .63 \\
\hline 16 & Most of my teachers really listen to what I have to say. & .17 & .42 & .55 & .63 \\
\hline 17 & In class, I often feel "put down" by my teachers. (reverse scored) & .12 & .32 & .46 & .52 \\
\hline 18 & In school, I often feel "put down" by other students. (reverse scored) & -.29 & -.06 & .53 & .41 \\
\hline
\end{tabular}

Note. Bolded values are factor loadings for items that comprised scores for Connection to Adults (Factor 1) or School Support (Factor 2).

and 13 were eliminated because of factor loadings on the structure matrix below .4. Internal consistency values at the fall, winter, and spring administrations were $.67, .69$, and .79 , respectively. Scores from the final items for each factor were averaged to produce a Connection to Adults score (factor 1 ) and a School Support score (factor 2) for each student at each time point.

\subsection{Procedure}

The measures of school connectedness were administered in fall (during the first week of school), winter (December), and spring (May) of the 2008-2009 school year. Homeroom teachers distributed surveys to all students present at the time of survey administration. Students completed surveys in approximately 30 minutes, and homeroom teachers collected surveys and returned them to the main offices of the schools (where investigators promptly picked them up) or directly to the investigators. At the end of the academic year, school district personnel provided a spreadsheet with GPA, attendance, and discipline referral data for each study participant.

\subsection{Missing data}

Student non-response on items resulted in high enough percentages that we were concerned with bias from non-response. These missing percentages ranged from $11.8 \%$ to $30.9 \%$ depending on the item and the time of administration (i.e., fall, winter, or spring). To determine the potential for bias due to missing responses, independent $t$-tests were used to compare the mean values of each item for subjects missing data on a descriptive variable. For example, children responded differently to Item 3 ("How many adults in this school do you feel comfortable talking to about problems having to do with your school work") based on whether or not they had responded to Item 1 ("How many adults in this school do you feel really know you as a person"), $t(288)=17.5, p<.001$. The $306 t$-tests (all 18 items by missing status on the other 17 variables) ranged from -19.2 to 17.5 with approximately $16 \%$ statistically significant at the .05 level. Little's missing completely at random (MCAR) test was statistically significant, indicating that the data 


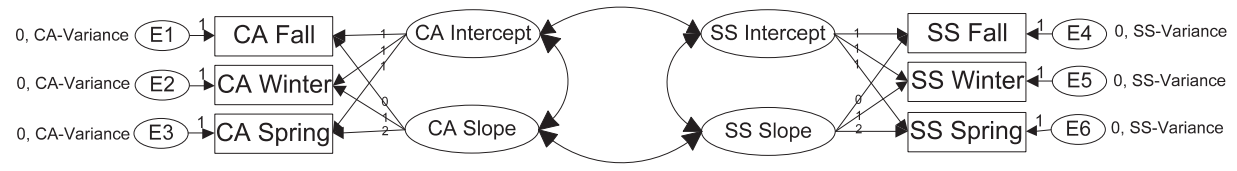

Fig. 1. Final measurement model (M3 in Table 2). $C A=$ Connection to Adults; SS = School Support. Two-way arrows represent covariances; one way arrows represent regression coefficients. Variables E1-E6 represent the error terms for the observed variables. The notations " 0 , CA-Variance" and " 0 , SS-Variance" indicate that the mean for each error term is fixed at 0 and the variances for each variable are constrained to be equal.

cannot be assumed to be MCAR, $\chi^{2}(4559)=4728.50, p=.04$. The Maximum Likelihood Expectation Maximization (EM) method was used to handle the missing data. This method has been found to produce valid statistical estimates if missing data are MAR or MCAR (Dempster, Laird \& Rubin, 1977).

\subsection{Data analysis}

\subsubsection{Model specification}

Because of the nested structure of the data (i.e., time points within students), and multiple dependent variables, latent growth curve modeling (LGCM) was chosen as the optimal method for handling the longitudinal data (Byrne, 2009). In the latent growth curve model (depicted in Fig. 1 and included in Fig. 2), the intercepts represent students' average perceptions of the school connectedness factors at the beginning of the year, and the slopes represent the average linear change in students' perceptions of the school connectedness factors across the year. The intercept and slope factors for Connection to Adults and School Support were latent factors in the model and were therefore represented by ellipses in the figure. The predictor variables (i.e., School and Gender), the Connection to Adults and School Support measures at each of the three time points, and the outcome variables (i.e., GPA, Absences, and Referrals) were all observed variables and therefore represented by boxes in Figs. 1 and 2. Separate growth curves for Connection to Adults and School Support were included in the model to allow for the estimation of students' initial status on both of these variables as well as growth across the three time points. Because the three time points were nearly equally spaced across the sixth-grade year (i.e., 4 months from Time 1 to Time 2; 4.5 months from Time 2 to Time 3), the model parameterizations for the slope factors were fixed at 0,1 , and 2 for both growth curves. The presence of only three time points per student limited inferences to the assumption of linear growth (Kline, 2010).

All models were estimated with AMOS 19 software (Arbuckle, 2010) using Maximum Likelihood estimation. Although the observed Connection to Adults and School Support variables were Likert-scale

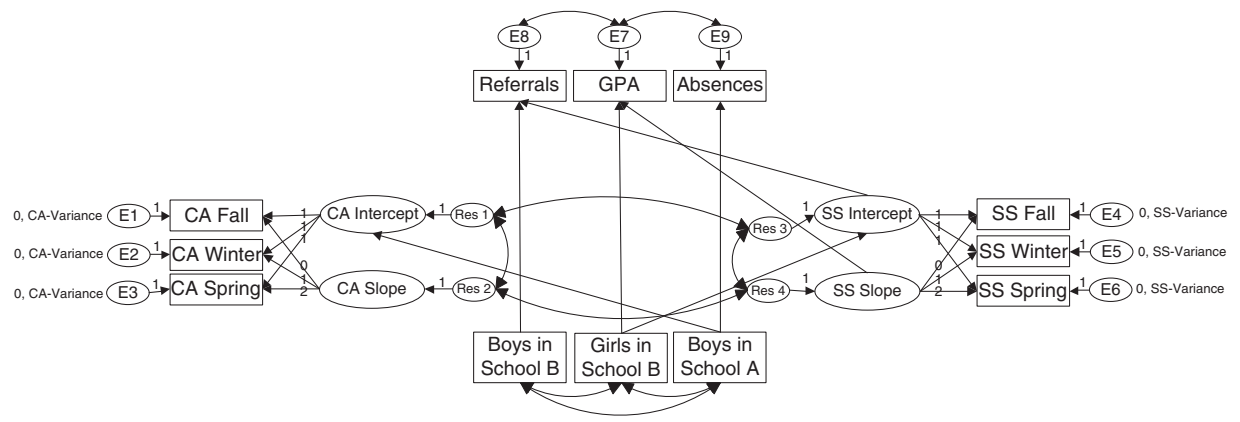

Fig. 2. Final structural model (S9d in Table 2). CA = Connection to Adults; SS = School Support. Only paths that significantly improved model fit, according to a variety of fit indices, are shown. For parameters tested but not retained, see rows in italics in Table 2. Twoway arrows represent covariances; one way arrows represent regression coefficients. Variables E1-E6 represent the error terms for the observed variables. The notations " 0 , CA-Variance" and " 0 , SS-Variance" indicate that the mean for each error term is fixed at 0 and the variances for each variable are constrained to be equal. Res 1-Res 4 represent the residual variances for each latent variable. 
categorical variables, we determined that this estimation method was valid because we had fewer than 25 observed variables at each time point (Bentler \& Chou, 1987; Mislevy, 1986), and we assumed that the underlying latent variables had a multivariate normal distribution (Bentler \& Wu, 1995). We therefore followed the advice of Chou, Bentler and Satorra (1991) and Hu, Bentler and Kano (1992) to treat these categorical variables as continuous. We also followed the advice of Byrne (2009) to compare the Maximum Likelihood estimates to Bayesian estimates to lend validity to the final model.

Table 2

Fit indices for latent growth curve analysis of parameter additions to the measurement and structural models.

\begin{tabular}{|c|c|c|c|c|c|c|}
\hline Model & Description of parameter tested & $\chi^{2}(d f)$ & $\Delta \chi^{2}$ & CFI & RMSEA $(90 \% \mathrm{CI})$ & ECVI \\
\hline MO & Initial model & $168.15(11)$ & - & .659 & $.208(.181, .237)$ & 0.608 \\
\hline M1 & Add intercept covariance & $65.96(10)$ & $-102.19 * * *$ & .879 & $.130(.102, .161)$ & 0.304 \\
\hline M2 & Add slope covariance & $44.47(9)$ & $-21.49^{* * *}$ & .923 & $.109(.079, .143)$ & 0.245 \\
\hline M3 & Constrain error variances to be equal to each other & $48.16(13)$ & 3.69 & .924 & $.091(.064, .119)$ & 0.231 \\
\hline So & $\begin{array}{l}\text { Initial structural model (M3 + DVs + Gender-School } \\
\text { groups) }\end{array}$ & $224.93(61)$ & - & .793 & $.090(.078, .103)$ & 0.860 \\
\hline S1 & Covariance between Referrals and GPA & $198.76(60)$ & $-26.17^{* * *}$ & .825 & $.084(.071, .097)$ & 0.787 \\
\hline S2a & Covariance between Referrals and Absences & $198.00(59)$ & -.76 & .825 & $.085(.072, .098)$ & 0.790 \\
\hline S2b & Covariance between GPA and Absences & $17.50(59)$ & $-28.26^{* * *}$ & .860 & $.076(.063, .089)$ & 0.707 \\
\hline$S 3 a$ & Regress Connection to Adults intercept on Boys in School B & $169.93(58)$ & -.57 & .859 & $.077(.063, .090)$ & 0.711 \\
\hline S3b & Regress Connection to Adults slope on Boys in School B & $17.44(58)$ & -.06 & .858 & $.077(.064, .090)$ & 0.713 \\
\hline S3c & Regress School Support intercept on Boys in School B & $17.50(58)$ & -.00 & .858 & $.077(.064, .090)$ & 0.713 \\
\hline S3d & Regress School Support slope on Boys in School B & $17.49(58)$ & -.01 & .858 & $.077(.064, .090)$ & 0.713 \\
\hline S3e & Regress Referrals on Boys in School B & $156.19(58)$ & $-14.31^{* * *}$ & .876 & $.072(.058, .085)$ & 0.669 \\
\hline $54 a$ & Regress GPA on Boys in School B & $154.29(57)$ & -1.90 & .877 & $.072(.058, .086)$ & 0.670 \\
\hline$S 4 b$ & Regress Absences on Boys in School B & $154.70(57)$ & -1.49 & .858 & $.072(.059, .086)$ & 0.671 \\
\hline$S 4 c$ & Regress Connection to Adults intercept on Girls in School B & $155.77(57)$ & -.42 & .876 & $.073(.059, .086)$ & 0.674 \\
\hline S4d & Regress Connection to Adults slope on Girls in School B & $155.57(57)$ & -.62 & .876 & $.073(.059, .086)$ & 0.673 \\
\hline S4e & Regress School Support intercept on Girls in School B & $149.28(57)$ & $-6.91^{*}$ & .884 & $.070(.057, .084)$ & 0.654 \\
\hline S5a & Regress School Support slope on Girls in School B & $149.11(56)$ & -.17 & .883 & $.071(.057, .085)$ & 0.660 \\
\hline$S 5 b$ & Regress Referrals on Girls in School B & $147.26(56)$ & -2.02 & .885 & $.070(.057, .084)$ & 0.654 \\
\hline S5c & Regress GPA on Girls in School B & $11.25(56)$ & $-39.03^{* * *}$ & .932 & $.054(.039, .069)$ & 0.542 \\
\hline S6a & Regress Absences on Girls in School B & $108.24(55)$ & -2.01 & .933 & $.054(.039, .069)$ & 0.542 \\
\hline S6b & Regress Connection to Adults intercept on Boys in School A & $107.07(55)$ & -3.18 & .934 & $.054(.038, .069)$ & 0.538 \\
\hline S7a & Regress Connection to Adults slope on Boys in School A & $107.01(54)$ & -.06 & .933 & $.055(.039, .070)$ & 0.544 \\
\hline$S 7 b$ & Regress School Support intercept on Boys in School A & $106.98(54)$ & -.09 & .933 & $.055(.039, .070)$ & 0.544 \\
\hline S7c & Regress School Support slope on Boys in School A & $106.82(54)$ & -.25 & .933 & $.055(.039, .070)$ & 0.544 \\
\hline S7d & Regress Referrals on Boys in School A & $104.88(54)$ & -2.19 & .936 & $.054(.038, .069)$ & 0.538 \\
\hline S7e & Regress GPA on Boys in School A & $106.44(54)$ & -.63 & .934 & $.054(.039, .069)$ & 0.542 \\
\hline S7f & Regress Absences on Boys in School A & $103.57(54)$ & -3.50 & .938 & $.053(.037, .068)$ & 0.534 \\
\hline S8a & Regress Referrals on Connection to Adults intercept & $102.39(53)$ & -1.18 & .938 & $.053(.038, .069)$ & 0.536 \\
\hline$S 8 b$ & Regress GPA on Connection to Adults intercept & $102.44(53)$ & -1.13 & .938 & $.053(.038, .069)$ & 0.536 \\
\hline$S 8 \mathrm{c}$ & Regress Absences on Connection to Adults intercept & $103.28(53)$ & -.29 & .937 & $.054(.038, .069)$ & 0.539 \\
\hline S8d & Regress Referrals on Connection to Adults slope & $103.03(53)$ & -.54 & .937 & $.054(.038, .069)$ & 0.538 \\
\hline S8e & Regress GPA on Connection to Adults slope & $101.92(53)$ & -1.65 & .938 & $.053(.037, .068)$ & 0.535 \\
\hline S8f & Regress Absences on Connection to Adults slope & $102.30(53)$ & -1.27 & .938 & $.053(.037, .069)$ & 0.536 \\
\hline S8g & Regress Referrals on School Support intercept & $100.37(53)$ & -3.20 & .940 & $.052(.036, .068)$ & 0.530 \\
\hline$S 9 a$ & Regress GPA on School Support intercept & $97.75(52)$ & -2.62 & .942 & $.052(.036, .067)$ & 0.528 \\
\hline$S 9 b$ & Regress Absences on School Support intercept & $100.35(52)$ & -.02 & .939 & $.053(.037, .069)$ & 0.536 \\
\hline S9c & Regress Referrals on School Support slope & $99.63(52)$ & -.74 & .940 & $.053(.037, .068)$ & 0.534 \\
\hline S9d & Regress GPA on School Support slope & $94.34(52)$ & $-6.03^{*}$ & .947 & $.050(.033, .066)$ & 0.518 \\
\hline S10a & Regress Absences on School Support slope & $93.63(51)$ & -.71 & .946 & $.050(.034, .067)$ & 0.522 \\
\hline
\end{tabular}

Note. Models M0-M3 represent parameters tested within the Measurement Model; Models S0-S10a represent parameters tested within the Structural Model. The $\Delta \chi^{2}$ value presents the difference between the previously best fitting model and the model tested at that step. Parameters tested in models shown in italics were not retained in subsequent models or used in model comparisons; parameters tested in models shown in bold were retained in subsequent models.

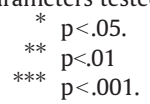




\subsubsection{Model analyses}

Model analyses were carried out in two stages. First, the measurement model (Models M0-M3 in Table 2), was examined prior to the addition of any structural components, as recommended by Byrne $(1998,2009)$. The initial measurement model (M0 in Table 2) allowed the slope and intercept within each school connectedness factor to covary freely. After making further respecifications to the measurement model (described in the Results section below), the final measurement model (Model M3 in Table 2; Fig. 1) was then carried over into the analyses of the full structural model. The initial structural model (Model S0 in Table 2) consisted of Model M3 and the six observed variables that were not part of the measurement model (GPA, Absences, Referrals, Boys in School A, Boys in School B, and Girls in School B). In Model S0, the six variables were modeled as being unrelated to each other, the Connection to Adults slope and intercept, and the School Support slope and intercept. Each step of the model analysis (Models S1-S10a in Table 2) consisted of the addition of a single parameter (i.e., regression coefficient or covariance). The addition of only one parameter at a time was important for minimizing the potential of attributing model variance to the wrong parameter (Byrne, 2009). Each subsequent model was compared to the previous model (e.g., Model S1 was compared to Model S0 in Table 2) to determine if the addition of the parameter resulted in better model fit (as recommended by Byrne, 2009). This approach allowed us to consider each subsequent model as being nested within the previous model, making the chi-square difference test a meaningful measure for all models. We therefore included the chi-square difference test as part of each analysis. Because our research questions were exploratory in nature, we tested every possible parameter in the model with a wide array of fit indices rather than relying solely on modification indices to direct the addition of model parameters.

\subsubsection{Model fit}

The chi-square difference test, the foundational test for comparing the unexplained variance in nested models (Hu \& Bentler, 1995), tests the null hypothesis that the covariance matrix reproduced according to the hypothesized model is the same as the observed covariance matrix. This test, however, has a wellknown limitation: as sample size increases, smaller differences will be magnified to the extent that unimportant differences, in terms of their practical significance, may be statistically significant (Bandalos, 1993). Because of this limitation, the chi-square test is not sufficient for comparing models. To address this limitation, we reported three other fit indices: Comparative Fit Index (CFI), Root Mean Square Error of approximation (RMSEA), and Expected Cross-Validation Index (ECVI). By incorporating such an array of fit indices into the analysis, threats to statistical conclusion validity (e.g., unreliability of measures, as in Shadish, Cook \& Campbell, 2002) were reduced.

We used recommended criteria (e.g., Hu \& Bentler, 1999) for each fit index to determine whether each model represented improvement over the former model. For the chi-square statistic, we looked for differences between chi-square across these models to be significant at least at the .05 probability level. When a parameter in the model met more stringent significance criteria (i.e., .01 and .001), we reported the higher confidence we had about the significance of the parameter. We also looked for CFI to increase; a cutoff of .95 was desired for the final model, as recommended by Hu and Bentler (1999). For RMSEA, we looked for the value to decrease; we considered a value of .05 or less to indicate good model fit and values between. 05 and .08 to indicate moderate fit (Browne \& Cudeck, 1993). ECVI values do not have any boundaries, so a general cutoff would not be appropriate. Instead, we followed the advice of Browne and Cudeck (1989) and compared ECVI values, considering lower values to indicate greater parsimony (i.e., the ability of the model to explain the most variance without including superfluous parameters). These indices were considered as a whole, rather than individually, and with respect to the theory behind the constructs being examined to minimize the likelihood of retaining unimportant constructs or discarding important ones.

\subsubsection{Predictor variables}

The research questions called for an examination of the predictive role of two indicators, Gender and School. To model Gender and School, three indicator variables were created: Boys in School A, Boys in School B, and Girls in School B. In this setup, Girls in School A served as the reference group. As an example, a statistically significant regression coefficient from Boys in School A to one of the outcome variables (e.g., GPA) would mean that Boys in School A had significantly different GPAs as compared to Girls in School A. In contrast, a nonsignificant regression coefficient would indicate no predictive differences between the 
particular Gender and School grouping as compared to Girls in School A. The predictor variables for Gender and School were allowed to covary freely in the model.

This setup allowed for comparisons of main effects for Gender and School as well as their interaction. Main effects of Gender could be seen if the regression coefficients for Boys in both School A and B were significant while the regression coefficient for Girls in School B on the same variable was nonsignificant. Likewise, main effects of School could be seen if the regression coefficients for both Boys and Girls in School B were significant while the regression coefficient for Boys in School A on the same variable was nonsignificant. Interaction effects could be seen in other combinations of significant and nonsignificant regression coefficients.

\section{Results}

\subsection{Measurement model}

The exploration of the measurement model consisted of adding covariance parameters between the intercepts and slopes of the latent factors. Both of these modifications yielded a better fitting model according to the chi-square difference test, CFI, RMSEA, and ECVI values (see Model M1 and Model M2, respectively, in Table 2). We then hypothesized that the variance of each factor at different time points should be consistent, so we tested whether they should be constrained to be equal to each other. The constraint of error variances (resulting in Model M3 in Table 2) increased the number of degrees of freedom; the resultant increase in model misfit (as revealed by the chi-square difference test; $\Delta \chi^{2}$ in Table 2) was not statistically significant. RMSEA indicated a better fitting model than the former models, but based on the criteria being used, the value of .091 indicated poor model fit. Similarly, CFI was higher than in the former models, but because the value had not reached the recommended level of .950, we concluded that additional model misfit remained to be explained. Model M3 (see fourth row of Table 2 and Fig. 1) was therefore retained as the best of the measurement models and became the baseline for the full structural model analyses.

\subsection{Structural model}

Model S0 (see fifth row of Table 2) consisted of the final measurement model (Model M3; see Fig. 1 and fourth row of Table 2), the three dependent variables (Referrals, GPA, Absences), and the three predictor variables for Gender and School; no covariances were included between the dependent variables, nor were any regression pathways to any of the dependent variables included. Table 2 presents the fit indices for the models resulting from the addition of each parameter (i.e., S1 through S10a). Parameters listed in italic font were not retained in subsequent models. Parameters retained in the subsequent model are listed in bold font.

All but three parameters retained in the final model (shown in Fig. 2 and listed as Model S9d in Table 2) reduced chi-square significantly, improved model fit according to the CFI and RMSEA indices, and improved the parsimony of the model according to ECVI (Table 2). The other three parameters retained in the final model were less straightforward. The first (shown as Model S6b in Table 2), the regression path from the Boys in School A indicator variable to the Connection to Adults intercept, reduced the chi-square by 3.18 points ( $p=.07$ ), which was not statistically significant. CFI increased, and ECVI decreased; the RMSEA value stayed the same, but the lower boundary for the 90\% confidence interval for RMSEA was slightly lower.

The evidence for the other two parameters in question was also mixed. The second parameter (shown as Model S7f in Table 2), the regression pathway from the Boys in School A indicator variable to Absences, increased CFI and reduced the RMSEA point estimate, the lower and upper bounds of the RMSEA 90\% confidence interval, and the ECVI. The chi-square value was also reduced, but only by 3.50 points $(p=.06)$, which was not statistically significant. Likewise, the third parameter (shown as Model S8g in Table 2), the regression path from the School Support intercept to Referrals, reduced chi-square by 3.20 points $(p=.07)$, which was not statistically significant. The CFI value increased while the ECVI value, the RMSEA point estimate, and the upper and lower boundaries for the RMSEA 90\% confidence interval were reduced.

We considered the statistical indicators for these three parameters to be mixed; however, because the parameters were conceptually meaningful to the research questions of interest, we concluded that sufficient evidence to exclude them was not available from these data. We therefore chose to retain them in subsequent models. 
The final model (shown in Fig. 2 and listed as Model S9d in Table 2) retained four other regression paths: from Boys in School B to Referrals (based on results from Model S3e in Table 2), from Girls in School B to the School Support intercept (based on results from Model S4e in Table 2), from Girls in School B to GPA (based on results from Model S5c in Table 2), and from the School Support slope to GPA (based on results from Model S9d in Table 2). Additionally, the covariances between Referrals and GPA and between GPA and Absences were retained (based on results from Models S1 and S2b in Table 2, respectively).

The fit of the final model was good based on all fit indices computed. The CFI value was .947, which was very close to the desired .950 . The RMSEA point estimate was .050 with a narrow confidence interval. ECVI was lower for the final model than for all previous models, indicating that the final model had not sacrificed parsimony for model fit.

Estimates for the final model (presented in Table 3) were computed using Maximum Likelihood estimation and compared to Bayesian estimates to determine whether the ordinal scales of the observed Connection to Adults and School Support variables created bias in the estimation process. The Bayesian estimates were very close to the Maximum Likelihood estimates, so we concluded that no further steps needed to be taken to reduce bias in the estimates.

\subsection{Research question 1}

The first research question asked about the extent to which students' perceptions of Connection to Adults and School Support changed across the sixth-grade year, as well as the extent to which Gender (controlling for School) predicted these changes. Estimates from the final model (presented in Table 3) showed that student perceptions of Connection to Adults had an average initial value of 2.20 (shown as Connection to Adults intercept in Table 3), indicating that students began the school year feeling connected to an average of two adults in the school. None of the indicator variables for Gender and School was a statistically significant predictor of Connection to Adults at the beginning of the year (i.e., Connection to Adults intercept in Table 3), as shown in the results for Models S3a, S4c, and S6b in Table 2. The average change over time for Connection to Adults (i.e., Connection to Adults slope in Table 3) was not statistically significant, $t(329)=-1.16, p=.25$, indicating that students' perceptions were relatively stable throughout the year.

Table 3

Maximum Likelihood and Bayesian estimates of final model shown in Fig. 2 and Model S9d in Table 2.

\begin{tabular}{|c|c|c|c|c|}
\hline \multirow[t]{2}{*}{ Variable } & \multicolumn{3}{|c|}{ Maximum Likelihood estimates } & \multirow{2}{*}{$\frac{\text { Bayesian estimates }}{\text { Mean }(S E)}$} \\
\hline & Mean $(S E)$ & $t$ & & \\
\hline Absences & $14.19(0.64)$ & $22.22^{* * *}$ & & $14.19(0.01)$ \\
\hline Connection to Adults intercept & $2.20(0.05)$ & $42.44^{* * *}$ & & $2.20(<0.01)$ \\
\hline Connection to Adults slope & $-0.04(0.03)$ & -1.16 & & $-0.04(<0.01)$ \\
\hline GPA & $2.79(0.05)$ & $60.24^{* * *}$ & & $2.79(<0.01)$ \\
\hline Referrals & $-1.31(2.36)$ & -0.56 & & $-1.24(0.03)$ \\
\hline School Support intercept & $2.07(0.03)$ & $82.16^{* * *}$ & & $2.07(<0.01)$ \\
\hline \multirow[t]{2}{*}{ School Support slope } & $-0.08(0.02)$ & $-5.51^{* * *}$ & & $-0.08(<0.01)$ \\
\hline & \multicolumn{3}{|c|}{ Maximum Likelihood estimates } & Bayesian estimates \\
\hline Regression path & $b(S E)$ & $t$ & $\beta$ & $b(S E)$ \\
\hline Boys in School $\mathrm{A} \rightarrow$ Absences & $-2.08(1.08)$ & -1.93 & -0.10 & $-2.07(0.01)$ \\
\hline Boys in School $\mathrm{A} \rightarrow$ Connection to Adults intercept & $-0.12(0.07)$ & -1.79 & -0.09 & $-0.12(<0.01)$ \\
\hline Girls in School B $\rightarrow$ GPA & $0.42(0.07)$ & $5.88^{* * *}$ & 0.27 & $0.43(<0.01)$ \\
\hline School Support slope $\rightarrow$ GPA & $0.73(0.31)$ & $2.36^{*}$ & 0.18 & $0.72(0.01)$ \\
\hline Boys in School B $\rightarrow$ Referrals & $2.79(0.67)$ & $4.19^{* * *}$ & 0.22 & $2.79(0.01)$ \\
\hline School Support intercept $\rightarrow$ Referrals & $1.83(1.11)$ & 1.65 & 0.11 & $1.79(0.01)$ \\
\hline Girls in School B $\rightarrow$ School Support intercept & $0.12(0.04)$ & $2.96^{* *}$ & 0.17 & $0.12(<0.01)$ \\
\hline
\end{tabular}

Note. $N=330$.

${ }_{*}^{*} \mathrm{p}<.05$.

$* *, \mathrm{p}<.01$.

$* * * \quad \mathrm{p}<.001$ 
Perceptions of School Support had an average initial value of 2.07 on a scale from 0 to 3 (School Support intercept in Table 3), indicating that students perceived a moderate level of School Support at the beginning of sixth grade. Girls in School B, however, had significantly higher perceptions of School Support at the beginning of the year ([School Support intercept] $+[b$ for Girls in School B $\rightarrow$ School Support intercept] $=2.07+0.12=2.19$ ) as compared to Girls in School A, $t(329)=2.96, p=.003$. Boys from both schools were not significantly different from Girls in School A. The change over time for School Support was negative and statistically significant (School Support slope $=-0.08, t[329]=-5.51, p<.001$ in Table 3), indicating that student perceptions of School Support declined significantly across the sixthgrade year. Over the course of the school year, students' perceptions of School Support decreased by an average of 0.16 points $(-.08 * 2=-0.16)$ or $7.7 \%$ ( 0.16 points out of the initial 2.07 points shown in Table 3 as the School Support intercept). This decline was consistent across Genders and Schools (see Models S3d, S5a, and S7c in Table 2).

\subsection{Research question 2}

The second research question examined whether Gender and initial status and growth of Connection to Adults and School Support predicted students' academic outcomes at the end of sixth grade, controlling for the School that students attended.

The interaction of Gender and School was statistically significantly related to Referrals (Boys in School $\mathrm{B} \rightarrow$ Referrals in Table 3) and GPA (Girls in School B $\rightarrow$ GPA in Table 3). Specifically, Boys in School B had significantly more Referrals during their sixth-grade year than Girls in School A, $t(329)=4.19, p<.001$. Boys in School A and Girls in School B were not significantly different from Girls in School A in terms of Referrals. Girls in School B had significantly higher GPAs than Girls in School A, $t(329)=5.88, p<.001$. The GPAs for boys at both schools were not significantly different from Girls in School A. Students' numbers of Absences did not significantly differ across Gender or School (see Models S4b, S6a, and S7f in Table 2).

School Support slope $\rightarrow$ GPA (see Table 3) was the only statistically significant regression pathway between the school connectedness factors and the student outcome variables in the final model (shown in Fig. 2 and S9d in Table 2), $t(329)=2.36, p=.02$. The average slope for School Support was -0.08 points, indicating that a student beginning the year with an average perception of School Support (2.07 points on a 3-point Likert scale) was predicted to have a year-end School Support perception equal to 1.91, controlling for all other factors in the model. The positive regression coefficient for School Support slope on GPA indicated that declines in perceptions of School Support (i.e., negative average slope) were associated with lower GPAs. In other words, the more decline that students perceived in School Support across the year, the lower their GPAs were at the end of the year. So the average GPA was predicted to be 2.79 for students with no decline in their perceptions of School Support, but students with an average decline in School Support had an expected end-of-year GPA of 2.67. Based on these results, we concluded that perceptions of School Support predicted GPA but not Referrals (see Models S8g and S9c in Table 2) or Absences (see Models S9b and S10a in Table 2). Perceptions of Connection to Adults were not statistically significant predictors of GPA (see Models S8b and S8e in Table 2), Absences (see Models S8c and S8f in Table 2), or Referrals (see Models S8a and S8d in Table 2).

\section{Discussion}

In this exploratory study of students' perceptions of school connectedness and their academic outcomes during the critical first year of middle school, three main findings emerged. First, students' perceptions of school support declined significantly across the sixth-grade year, regardless of student gender or school attended. Second, sixth-grade students who reported less than average decline, or growth, in school support across the year had higher end-of-year GPAs than students who experienced more than average decline in school support. Third, although it depended on which school they attended, girls reported higher school connectedness at the beginning of sixth grade and fared better than their male counterparts on measures of academic success and behavioral outcomes at the end of the year. Each of these findings will be discussed below.

Both boys and girls reported similar levels of decline in their perceptions of school support across sixth grade, which is consistent with previous research showing that students feel less connected to teachers and 
the school environment after the transition to middle school (Anderman, 2003; Furrer \& Skinner, 2003). What is especially striking about this finding is that students' initial perceptions of school support were collected within the first week of their sixth-grade year, meaning that they had little interaction within their new school environment and were most likely relying on previous experiences in their elementary school classrooms to form their opinions. Sadly, after students spent several months in the middle school setting and had more opportunities to get to know their teachers, their perceptions of how much support they received from their teachers and the school environment in general declined significantly.

Although students felt less supported by their school environments across the sixth-grade year, changes in perceived school support emerged as a predictor of students' end-of-year GPAs. Specifically, students who reported less decline, or growth, in school support across the year earned higher grades in sixth grade than students who reported greater declines in school support, suggesting that this sense of school support may be protective against negative outcomes typically associated with the transition to middle school. These findings support Deci and Ryan's (2000) self-determination theory in that students' sense of relatedness in their school environment was important to their school success. Additionally, these findings are congruent with burgeoning research demonstrating the importance of students' connection to school for positive academic outcomes during the middle school years (Crosnoe et al., 2004; Davis, 2006; Furrer \& Skinner, 2003; Patrick et al., 2007; Roeser et al., 1996). Collectively, these preliminary findings point to a specific type of school connection-perceptions of a supportive school environment-for ameliorating students' negative outcomes during the transition to middle school. What is significant from this study is that the protective factor that emerged (i.e., school support) is an environmental factor that is changeable at the school level. Specifically, faculty and staff can work to create an environment in which students feel more cared for and supported when they are at school.

It is especially interesting that how much students changed in perceived school support was more important to their academic success than their perceptions of school support at the beginning of sixth grade. Thus, even if a student begins his or her middle school career perceiving little school support, these initial feelings are not as important to later student success as the changes that he or she may experience in school support over the course of sixth grade. This finding is encouraging for teachers and other school adults who have the course of a school year to build relationships with students and help them feel comfortable and confident at school. These findings, however, also suggest that during the sixth-grade year, teachers, administrators, and school psychologists and counselors may need to do more to prevent declines in perceived support.

Interestingly, results showed that connection to adults remained stable across the year and did not predict students' academic outcomes. Students' connection to adults was measured by how many adults they felt connected to in their school environment and was therefore a frequency count of their relationships with school adults. Given that students' perceived connection to adults was measured the first week of their sixthgrade year when they would have presumably known very few adults at their new middle school, one would expect that students would know and feel comfortable with more school adults as the school year progressed. However, this presumption was not the case, and the fact that students felt connected to the same number of adults at the end of the year as during the first week of school is in itself a cause for concern. Surprisingly, though, students' perceived connectedness to adults (both initially and across the year) was not related to their academic outcomes. This finding may be due to the measurement used (i.e., a frequency count) such that the quality of students' relationships in their school environment (i.e., school support) was more important than the quantity of relationships they shared with adults (i.e., connection to adults). For example, having high-quality, close relationships with one or two adults at school may be more protective than having four or five acquaintance relationships. Another possibility is that students' relationships with peers are more important than their relationships with adults as they transition into adolescence. In fact, recent research suggests that students' academic motivation is more strongly linked to their peer relationships in middle school than in elementary school (Molloy, Gest \& Rulison, 2011). As peer relationships increase in importance to middle school students, it could be that connectedness with a positive peer group is a stronger contributor to academic success than connectedness with school adults, although this question warrants further research.

We also found that girls seemed to weather the transition to middle school better than boys in terms of academic achievement and behavioral outcomes. Girls had higher end-of-year GPAs and fewer discipline referrals, although this finding applied only to students in School B, which was the school that offered the competitive magnet program. This finding is consistent with previous research showing that girls outperform 
boys throughout school in terms of grades earned (American Association of University Women Educational Foundation, 1998; Perkins, Kleiner, Roey \& Brown, 2004) and experience fewer disciplinary problems at school (Crosnoe et al., 2004). Boys, then, seem to be particularly at risk for negative outcomes across this important transitional period.

\subsection{Limitations}

Several limitations existed in the present study. Perhaps most important to mention, this study was exploratory in nature, and therefore, cross-validation is needed to address potential issues with sample dependency. For example, our sample included students from only two schools from one school district, and some demographic groups (e.g., Latino students) were under-represented in the sample. Although $22 \%$ of school-aged youth in the United States are Latino (U.S. Census Bureau, 2008), Latino students composed less than $7 \%$ of the current sample. Such a limited sample in terms of racial/ethnic representation and geographic locale may reduce the generalizability of the findings. It is also important to note that one school was a magnet school, and although magnet students were not included in this study and school was controlled for in all analyses, it is possible that the presence of the magnet program may have affected the school environment for all students attending the school.

In addition to sample dependency issues, there were a few other limitations that warrant discussion. First, we only had measures of GPA, absences, and discpline referrals at the end of the school year and were not able to control for pre-existing differences in these outcome variables. Second, the non-experimental design of the study (i.e., "business as usual") reduced our ability to establish any causal inferences. Instead, we limited our findings to relational inferences. Third, although referrals were coded according to district policies, the level of tolerance for misbehavior varies widely between teachers and schools. Thus, infractions resulting in referral in one school may not have had the same outcome in the other school. Finally, there were some limitations related to the data collection procedures. Specifically, students filled out the school connectedness surveys in their classrooms in the presence of their teachers. The mere presence of the teacher may have affected the way that students responded to questions asking about their relationships with teachers and other school adults (e.g., a social desirability effect).

\subsection{Implications and future directions}

Preliminary findings from this study point to the important role that teachers and other school adults (e.g., school psychologists) have in promoting positive academic outcomes during the transition to middle school. Although, on average, perceived school support declined significantly across sixth grade, students who experienced less than average decline, or growth, in perceived school support across the year tended to have higher GPAs than students who experienced more than average decline in perceived school support. Thus, the present study shows that middle school students' connectedness to school is a critical component of their educational experience and that students can benefit from close, supportive relationships at school beyond the elementary school years.

Congruent with theoretical work on the value of social support for healthy outcomes (Baumeister \& Leary, 1995; Deci \& Ryan, 2000), this study has significant implications for the field of education and teacher training by highlighting the importance of a supportive school environment as students transition from elementary to middle school and from childhood into adolescence. Teacher preparation programs and professional development activities should include training on the significance of middle school teachers' relationships with their students, including techniques and strategies that teachers can use to support students' personal development during this transition. Given that perceived school support also entailed how comfortable and confident students felt while at school, it is important for teachers and staff in the middle school setting to be knowledgeable and skilled in facilitating a positive, supportive, and inclusive environment to enable students to express themselves as individuals and feel confident in their abilities. Although there is currently little research directly linking teachers' professional development with students' feelings of school connectedness, recent research does show that teachers who receive training on how to foster students' connection to school are more likely to use connection-building strategies (e.g., using students' first names, modeling respectful behaviors and interactions) that are linked with more positive classroom and school environments for students (Vidourek, King, Bernard, Murnan \& Nabors, 2011). Future research should continue investigating 
the effectiveness of professional development activities in enhancing school climate and connectedness, in addition to examining which particular teacher behaviors most strongly contribute to students' beliefs that their teachers care about them on both an academic and personal level.

Additionally, given that sixth-grade boys reported more negative outcomes across sixth grade than did girls (e.g., lower grades and more discipline problems), particular attention needs to be paid to protective factors that may buffer against boys' risks for academic and behavioral problems. Interestingly, at School B, boys also perceived a less supportive school environment at the beginning of the year as compared to girls, which would suggest that middle school teachers and other school adults may need to focus on building more supportive relationships with boys. Additionally, it could be that school connectedness is not as strong of a protective factor for boys as it is for girls among some student populations (e.g., among schools serving high poverty populations as in this sample). The gender of the teacher may also influence the extent to which teacher and school support serve as a protective factor for boys versus girls. For the schools included in this study, a large majority (72\%) of the teachers were women, which may help strengthen the protective power of school connectedness for girls more than boys. Another possibility is that peer relationships and relationships outside school may play a stronger role than does the school environment in predicting student outcomes for boys in particular. As is evident from this discussion, further investigation is needed to unearth the complex connections between peer influences, teacher caring, school environments, and academic and behavioral outcomes for middle school boys.

The present study has several impliations specifically related to the work of school psychologists in the middle school setting. First, it is important for school psychologists to inform and educate teachers, administrators, and staff in their schools as to the role that school support plays in contibuting to students' academic success, as well as the fact that sixth-graders are vulnerable to declines in perceived school support across this transitional period. Greater awareness of these issues may help those who work in middle schools to be more attuned to the nature of their school environment and the relationships they are building with students. Second, school psychologists can coordinate or even lead professional development activites related to fostering positive classroom and school climates. For example, practices implemented as part of the Responsive Classroom approach (e.g., class meetings each morning where the teacher and students greet one another and share personal news, classroom rules and procedures jointly decided upon by the teacher and the students, classroom organization that facilitates social interaction and cooperation) are associated with more positive perceptions of the classroom and school environments by students in elementary grades (Brock, Nishida, Chiong, Grimm \& RimmKaufman, 2008). School psychologists can help other faculty and staff members incorporate such classroom and school practices into their routines as part of regular professional development and training. Third, school psychologists can form personal relationships with the sixth-grade students who they help on a regular basis, thereby contributing to students' sense of a supportive school environment across both academic and social-emotional domains.

Overall, this exploratory study builds on other work implicating school connectedness as critical for young adolescents' positive adjustment to middle school (Davis, 2006; Roeser et al., 1996; Ryan et al., 1994), and extends previous findings regarding the importance of school connectedness to students from high poverty backgrounds. Indeed, the present study suggests that perceived school support may potentially serve as a protective factor for first-year middle school students who are at risk for negative academic outcomes due to poverty.

\section{References}

Alspaugh, J. (1998). Achievement loss associated with the transition to middle school and high school. The Journal of Educational Research, 92, 20-25.

American Association of University Women Educational Foundation (1998). Gender gaps: Where schools still fail our children. Washington, DC: Author.

Anderman, L. (2003). Academic and social perceptions as predictors of change in middle school students' sense of school belonging. The Journal of Experimental Education, 72, 5-22.

Anderman, E., Maehr, M., \& Midgley, C. (1999). Declining motivation after the transition to middle school: Schools can make a difference. Journal of Research \&' Development in Education, 32, 131-147.

Appleton, J., Christenson, S., \& Furlong, M. (2008). Student engagement with school: Critical conceptual and methodological issues of the construct. Psychology in the Schools, 45, 369-386. 
Arbuckle, J. L. (2010). IBM SPSS AMOS 19 [Software]. Crawfordville, FL: AMOS Development Corporation.

Bandalos, D. (1993). Factors influencing cross-validation of confirmatory factor analysis models. Multivariate Behavioral Research, 28, 351-374.

Battistich, V., Solomon, D., Kim, D., \& Watson, M. (1995). Schools as communities, poverty levels of student populations, and students' attitudes, motives, and performance: A multilevel analysis. American Educational Research Journal, 32, 627-658.

Baumeister, R., \& Leary, M. (1995). The need to belong: Desire for interpersonal attachments as a fundamental human motivation. Psychological Bulletin, 117, 497-529.

Bentler, P. M., \& Chou, C. P. (1987). Practical issues in structural modeling. Sociological Methods E Research, 16, 78-117.

Bentler, P. M., \& Wu, E. J. C. (1995). EQS for Windows: User's guide. Encino, CA: Multivariate Software, Inc..

Bolland, J., Bryant, C., Lian, B., McCallum, D., Vazsonyi, A., \& Barth, J. (2007). Development and risk behavior among African American, Caucasian, and mixed-race adolescents living in high poverty inner-city neighborhoods. American Journal of Community Psychology, 40, 230-249.

Brock, L., Nishida, T., Chiong, C., Grimm, K., \& Rimm-Kaufman, S. (2008). Children's perceptions of the classroom environment and social and academic performance: A longitudinal analysis of the contribution of the "Responsive Classroom" approach. Journal of School Psychology, 46, 129-149.

Browne, M., \& Cudeck, R. (1989). Single sample cross-validation indices for covariance structures. Multivariate Behavioral Research, 24, 445-455.

Browne, M., \& Cudeck, R. (1993). Alternative ways of assessing model fit. In K. A. Bollen, \& J. S. Long (Eds.), Testing structural equation models (pp. 136-162). Newbury Park, CA: Sage.

Byrne, B. (1998). Structural equation modeling with LISREL, PRELIS, and SIMPLIS: Basic concepts, applications, and programming. Mahwah, NJ: Erlbaum.

Byrne, B. (2009). Structural equation modeling with AMOS: Basic concepts, applications, and programming (2nd ed.). New York, NY: Routledge.

Catalano, R., Haggerty, K., Oesterle, S., Fleming, C., \& Hawkins, J. (2004). The importance of bonding to school for healthy development: Findings from the social development research group. Journal of School Health, 74, 252-261.

Chou, C. P., Bentler, P. M., \& Satorra, A. (1991). Scaled test statistics and robust standard errors for non-normal data in covariance structure analysis: A Monte Carlo study. British Journal of Mathematical and Statistical Psychology, 44, 347-357.

Crosnoe, R., Johnson, M., \& Elder, G. (2004). Intergenerational bonding in school: The behavioral and contextual correlates of student-teacher relationships. Sociology of Education, 77, 60-81.

Davis, H. (2003). Conceptualizing the role and influence of student-teacher relationships on children's social and cognitive development. Educational Psychologist, 38, 207-234.

Davis, H. (2006). Exploring the contexts of relationship quality between middle school students and teachers. The Elementary School Journal, 106, 193-223.

Deci, E., \& Ryan, R. (2000). The 'what' and 'why' of goal pursuits: Human needs and the self-determination of behavior. Psychological Inquiry, 11, 227-268.

Demaray, M., Malecki, C., Rueger, S., Brown, S., \& Summers, K. (2009). The role of youth's ratings of the importance of socially supportive behaviors in the relationship between social support and self-concept. Journal of Youth and Adolescence, 38, 13-28.

Dempster, A., Laird, N., \& Rubin, D. (1977). Maximum likelihood from incomplete data via the EM algorithm. Journal of the Royal Statistical Society, 39, 1-38.

Diaz, J. (2005). School attachment among Latino youth in rural Minnesota. Hispanic Journal of Behavioral Sciences, 27, $300-318$.

Eccles, J., Lord, S., Roeser, R., \& Barber, B. (1997). The association of school transitions in early adolescence with developmental trajectories through high school. In J. Schulenberg, J. Maggs, \& K. Hurrelmann (Eds.), Health risks and developmental transitions during adolescence (pp. 283-320). New York, NY: Cambridge University Press.

Ewing, A., \& Taylor, A. (2009). The role of child gender and ethnicity in teacher-child relationship quality and children's behavioral adjustment in preschool. Early Childhood Research Quarterly, 24, 92-105.

Furrer, C., \& Skinner, E. (2003). Sense of relatedness as a factor in children's academic engagement and performance. Journal of Educational Psychology, 95, 148-162.

Gutman, L., \& Midgley, C. (2000). The role of protective factors in supporting the academic achievement of poor African American students during the middle school transition. Journal of Youth and Adolescence, 29, 223-248.

Hu, L., \& Bentler, P. M. (1995). Evaluating model fit. In R. Hoyle (Ed.), Structural equation modeling: Concepts, issues, and applications (pp. 76-99). Thousand Oaks, CA: Sage.

Hu, L., \& Bentler, P. M. (1999). Cutoff criteria for fit indexes in covariance structure analysis: Conventional criteria versus new alternatives. Structural Equation Modeling: A Multidisciplinary Journal, 6, 1-55.

Hu, L., Bentler, P. M., \& Kano, Y. (1992). Can test statistics in covariance structure analysis be trusted? Psychological Bulletin, 112, 351-362.

Jennings, G. (2003). An exploration of meaningful participation and caring relationships as contexts for school engagement. California School Psychologist, 8, 43-52.

Jia, Y., Way, N., Ling, G., Yoshikawa, H., Chen, X., Hughes, D., et al. (2009). The influence of student perceptions of school climate on socioemotional and academic adjustment: A comparison of Chinese and American adolescents. Child Development, 80, 1514-1530.

Kline, R. (2010). Principles and practice of structural equation modeling (3rd ed.). New York, NY: Guilford Press.

LaGuardia, J., Ryan, R., Couchman, C., \& Deci, E. (2000). Within-person variation in security of attachment: A self-determination theory perspective on attachment, need fulfillment, and well-being. Journal of Personality and Social Psychology, 79, 367-384

Libbey, H. (2004). Measuring student relationships to school: Attachment, bonding, connectedness, and engagement. Journal of School Health, 74, 274-283.

Loukas, A., Roalson, L., \& Herrera, D. (2010). School connectedness buffers the effects of negative family relations and poor effortful control on early adolescent conduct problems. Journal of Research on Adolescence, 20, 13-22.

McNeely, C., \& Falci, C. (2004). School connectedness and the transition into and out of health-risk behavior among adolescents: A comparison of social belonging and teacher support. Journal of School Health, 74, 284-292.

Mislevy, R. J. (1986). Recent developments in the factor analysis of categorical variables. Journal of Educational Statistics, 11, 3-31. 
Molloy, L., Gest, S., \& Rulison, K. (2011). Peer influences on academic motivation: Exploring multiple methods of assessing youths' most "influential" peer relationships. Journal of Early Adolescence, 31, 13-40.

O'Connor, B. P. (2000). SPSS and SAS programs for determining the number of components using parallel analysis and Velicer's MAP test. Behavior Research Methods, Instrumentation, and Computers, 32, 396-402.

Olsson, E. (2009). The role of relations: Do disadvantaged adolescents benefit more from high-quality social relations? Acta Sociologica, 52, 263-286.

Pagani, L., Boulerice, B., Vitaro, F., \& Tremblay, R. (1999). Effects of poverty on academic failure and delinquency in boys: A change and process model approach. Journal of Child Psychology and Psychiatry, 40, 1209-1219.

Patrick, H., Ryan, A., \& Kaplan, A. (2007). Early adolescents' perceptions of the classroom social environment, motivational beliefs, and engagement. Journal of Educational Psychology, 99, 83-98.

Perkins, R., Kleiner, B., Roey, S., \& Brown, J. (2004). The high school transcript study: A decade of change in curricula and achievement, 1990-2000. Report no. NCES 2004455. Washington, DC: US Department of Education, National Center for Education Statistics.

Reddy, R., Rhodes, J. E., \& Mulhall, P. (2003). The influence of teacher support on student adjustment in the middle school years: A latent growth curve study. Development and Psychopathology, 15, 119-138.

Resnick, M., Bearman, P., Blum, R., Bauman, K., Harris, K., Jones, J., et al. (1997). Protecting adolescents from harm: Findings from the National Longitudinal Study on Adolescent Health. Journal of the American Medical Association, 278, 823-832.

Roeser, R., Midgley, C., \& Urdan, T. (1996). Perceptions of the school psychological environment and early adolescents' psychological and behavioral functioning in school: The mediating role of goals and belonging. Journal of Educational Psychology, 88, 408-422.

Rudasill, K., Reio, T., Stipanovic, N., \& Taylor, J. (2010). A longitudinal study of student-teacher relationship quality, difficult temperament, and risky behavior from childhood to early adolescence. Journal of School Psychology, 48, 389-412.

Rueger, S., Malecki, C., \& Demaray, M. (2010). Relationship between multiple sources of perceived social support and psychological and academic adjustment in early adolescence: Comparisons across gender. Journal of Youth and Adolescence, 39, 47-61.

Ryan, R., Stiller, J., \& Lynch, J. (1994). Representations of relationships to teachers, parents, and friends as predictors of academic motivation and self-esteem. Journal of Early Adolescence, 14, 226-249.

Sanders, M., \& Jordan, W. (2000). Student-teacher relations and academic achievement in high school. In M. Sanders (Ed.), Schooling students placed at risk: Research, policy, and practice in the education of poor and minority adolescents (pp. 65-82). Mahwah, NJ: Erlbaum.

Shadish, W. R., Cook, T. D., \& Campbell, D. T. (2002). Experimental and quasi-experimental design. Boston, MA: Houghton Mifflin.

Stevens, J. P. (2002). Applied multivariate statistics for the social sciences (4th ed.). Mahwah, NJ: Erlbaum.

Suldo, S., Friedrich, A., White, T., Farmer, J., Minch, D., \& Michalowski, J. (2009). Teacher support and adolescents' subjective wellbeing: A mixed-methods investigation. School Psychology Review, 38, 67-85.

U.S. Census Bureau (2008). An older and more diverse nation by mid-century. Retrieved October 12, 2008, from http://www.census. gov/Press-Release/www.releases/archives/population/012496.html

Van Ryzin, M., Gravely, A., \& Roseth, C. (2009). Autonomy, belongingness, and engagement in school as contributors to adolescent psychological well-being. Journal of Youth and Adolescence, 38, 1-12.

Vidourek, R., King, K., Bernard, A., Murnan, J., \& Nabors, L. (2011). Teachers' strategies to positively connect students to school. American Journal of Health Education, 42, 116-126.

Voisin, D., Salazar, L., Crosby, R., Diclemente, R., Yarber, W., \& Staples-Horne, M. (2005). Teacher connectedness and health-related outcomes among detained adolescents. Journal of Adolescent Health, 37, 17-23.

Way, N., Reddy, R., \& Rhodes, J. (2007). Students' perceptions of school climate during the middle school years: associations with trajectories of psychological and behavioral adjustment. American Journal of Community Psychology, 40, 194-213.

Wentzel, K. (2002). Are effective teachers like good parents? Teaching styles and student adjustment in early adolescence. Child Development, 73, 287-301.

Wentzel, K., Battle, A., Russell, S., \& Looney, L. (2010). Social supports from teachers and peers as predictors of academic and social motivation. Contemporary Educational Psychology, 35, 193-202.

Wigfield, A., Eccles, J., Mac Iver, D., Reuman, D., \& Midgley, C. (1991). Transitions during early adolescence: Changes in children's domain-specific self-perceptions and general self-esteem across the transition to junior high school. Developmental Psychology, 27, 552-565.

Wigfield, A., Lutz, S., \& Wagner, A. (2005). Early adolescents' development across the middle school years: Implications for school counselors. Professional School Counseling, 9, 112-119. 